\title{
Social Learners' Profiles in a Distance Learning System Powered by a Social Network
}

\author{
HROR Naoual \\ Laboratory Systems and Telecommunications Engineering \\ Of Decision, University IbnTofail, \\ Kenitra, MOROCCO
}

\begin{abstract}
This work is integrated into the general problem of the research systems of distance learning; and more particularly in the monitoring and the positioning of social profile learners in a distance learning system powered by a social network. In this article, we propose a model multi-entry to determine the learners' profile and positioning his social type. This template allows you to exploit the different traces generated by a learner in the platform and produce indicators on his own profile.
\end{abstract}

Our approach leverages the tools of the fuzzy set theory, the modal and temporal logic. The motivation of this research is to create a tool which helps the tutor to better observe and follow the actions of the learners at the level of the learning platform, and to anticipate potential discouragements or abandonment of the learner.

Keywords-Distance learning system; Social profile; Traces; fuzzy; social network

\section{INTRODUCTION}

Our research focuses on the IT environments for human learning , and particularly on the assistance of learners in their learning journey online. This mode of learning has profoundly benefited from the important technological innovation of the 21 th century. Despite this great innovation, the dropout rate of learners remains high. According to Bernatchez and Gendreau [1], this rate can vary from 37 to $50 \%$ depending on the context of learning.

The purpose of our research work firstly consists in defining the needs referred by internet in social networks, and determine the various inputs offered by these networks, and secondly in integrating the functionality provided by these systems in the available platforms of learning online.

We will then be offering the learner a system of comprehensive learning which responds to both the cognitive and social needs, and then we are aiming to exploit the traces produced on these new workspaces, and generating indicators to help the tutor to better follow the social behavior of learners within these complex systems.

In the first paragraph, we are presenting the social needs of internet users, and then we are charting a state of the art on the platforms of distance learning that have used social networks. In the second paragraph, we present the most important features of social networks that we are trying to exploit in our target system.

\author{
OUMAIRA Ilham/MESSOUSSI Rochdi \\ Laboratory Systems and Telecommunications Engineering \\ Of Decision, University IbnTofail, \\ Kenitra, MOROCCO
}

The third paragraph describes the architecture of our Model System of the social profiles of learners SMPSA. The last paragraph is dedicated to the modeling of traces collected by the method of fuzzy logic, to produce the learners' profiles.

\section{SOCIAL NETWORKS (SN)}

\section{A. The Features of Social Networks}

All the social networks attract surfers by their features, below you will find a list of the typical features of a social networking site like Facebook, Tiwtter, Google, FriendFeed... Each platform provides these features. Next we propose a brief description of some features.

\section{- Sharing Documents}

Most of the social networks offer the feather of sharing documents; a member of the SN can upload a text file, PDF, or even an image ... The other members will be able to download it as well, send back a new version or display it directly.

\section{- Sharing Comments}

Comment modules allow your users to interact with the content and other members of your social network. Our flexible infrastructure enables administrators to attach comments to virtually any kind of content: wall notes, blog posts, images, etc[5].

\section{- Sharing Tags}

Similar to comments, tags can be attached to different types of content, allowing users to build an independant form of navigation and/or categorization. [5]. The surfer can use the tags "I like" "like" "seen" etc, if he likes a shared document or a comment, he can mark it with a tag; it is a simple way to express his point of view.

Thanks to the previously mentioned features, Social networks like Facebook, Twitter and YouTube have rapidly become a part of many people's everyday lives, especially for those younger generations, like students, who have grown up with so much technology at their fingertips.

There are lots of possible reasons for student's social media usage - to stay in touch with friends, share a funny video, keep up with news, and build professional contacts. Yet, why do students use social media? This was one of the questions we attempted to answer in the next paragraph. 


\section{B. The Sociol Needs of Surfers}

HyderKabani, Shaamah, author of The Zen of Social Media Marketing [6], affirms the existence of two reasons that prompt users to integrate a social network:

- The expression of the identity: internet users need to put their identity in value, by trying to be better than other.

- The need to keep in touch with their friends and create new bonds of friendship.

Julie Schlack, Michel Jennings and Manila Austin [7] have also cited six essential social needs which are pushing the internet users to join a social network:

- Express their identities using the profiles.

- Help the others and ask them for help.

- Find people sharing the same center of interest.

- Create networks and a relationship with the each other.

- Develop a true sense of belonging to a community.

- Be reassured on their values, by having the feeling being useful and having influence on the world that surrounds them.

Similar results have been deducted by a study made by DacharyCarey[8] :

- Help connected people.

- Search for the popularity.

- Build a community.

- Marketing

- $\quad \ldots$

The social needs of a learner vary from an online system to another (learning platform, games application etc. ) and from a context to another (obtain an academic degree, training of language etc. ), also these needs vary between the systems of learning and the sites of social networks. For this purpose, we have proposed to classify them according to the diagram below (Figure 1): the degrees of the color of the arrows depict the importance of the need

\section{DistanCE LEARNING PlatForms SUPPLIED By A SOCIAL NETWORK}

The integration of social networks in the platforms of distance learning is a recent approach; several works [9] [10] [11] have been established on this new method of learning. Among these works, we cite the experience of the University of Leicester, one of these teachers has opened the social network "FriendFeed" with the students to provide them with information relating to the course - links, folders...

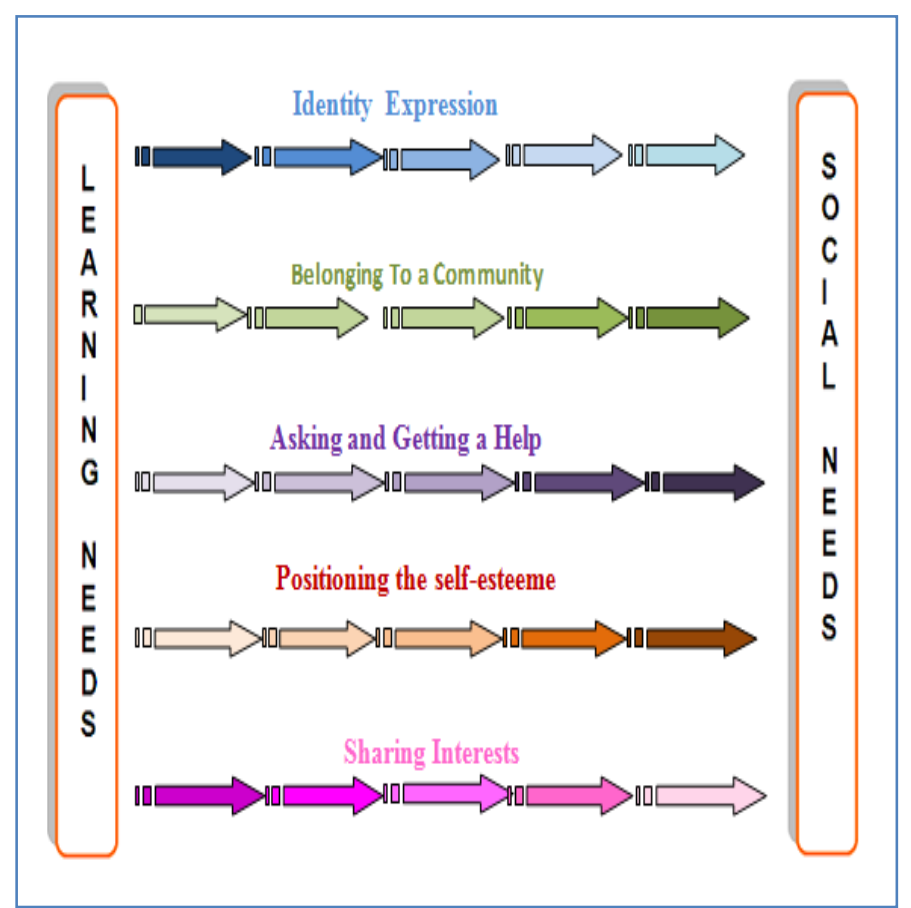

Fig.1. The social Needs

Each participant has a personal page, in which he can indicate the status of their work and the difficulties encountered [10].

Another experiment launched by a teacher from the University of Vienna, who asks his students to make feedbacks on his course through the site of micro-blogging in order to assess the success of his lessons [12].

These experiences have highlighted the general results, like the importance of the attendance rate of network, the regularity of connected pupils, the usefulness of the comments to improve the job ... [13].

However, this information is still insufficient for the tutor to have a visibility on the social participation of the learner at the level of the platform that will help him to better intervene during the training.

In our university, we work with the platform "Moodle " , a free, online Learning Management system[14] ,Technically, to satisfy our need to feed our distance learning platform "Moodle" with a social network, we have made studies about open sources social networks; In the next paragraph, we present the summary of our research.

\section{The Social Networks Open Source}

Currently, several platforms of social networks are used. Below we show a few examples [15]: 
TABLE.I. The Platforms of SOCIAL Networks OPEN SOURCES

\begin{tabular}{|l|l|l|c|l|}
\hline $\begin{array}{l}\text { Social } \\
\text { Network }\end{array}$ & Langue & Technology & $\begin{array}{l}\text { Compatibili } \\
\text { ty Moodle }\end{array}$ & $\begin{array}{l}\text { Docume- } \\
\text { ntation }\end{array}$ \\
\hline Elgg [16] & English & $\begin{array}{l}\text { Apache,MySQL, } \\
\text { PHP }\end{array}$ & Yes & Low \\
\hline Oxwall [17] & $\begin{array}{l}\text { English/ } \\
\text { German }\end{array}$ & $\begin{array}{l}\text { Apache,MySQL, } \\
\text { PHP }\end{array}$ & Yes & Low \\
\hline $\begin{array}{l}\text { LiveStreet } \\
\text { [18] }\end{array}$ & $\begin{array}{l}\text { English/ } \\
\text { Russian }\end{array}$ & $\begin{array}{l}\text { Apache,MySQL, } \\
\text { PHP }\end{array}$ & Yes & Low \\
\hline $\begin{array}{l}\text { Mahara } \\
{[\mathbf{1 9}]}\end{array}$ & $\begin{array}{l}\text { French } \\
\text { /English }\end{array}$ & $\begin{array}{l}\text { Apache,MySQL, } \\
\text { PHP }\end{array}$ & Yes & Strong \\
\hline Arab & & & \\
\hline
\end{tabular}

- Mahara is fully featured electronic portfolio, weblog; resume builder, and social networking system for connecting users and creating online communities.

- Elgg is an open source social networking platform developed for LAMP (Linux, Apache, MySQL, PHP) which encompasses weblogging, file storage, RSS aggregation, personal profiles, FOAF functionality and more.

- Oxwall is a free and open source community software distributed under the Common Public Attribution License. It is written in PHP and is used as a platform for social networking and community sites.

- LiveStreet is open team collaboration software that uses social networking to unify team workspaces, written in PHP, Javascript and MySQL.

To make our choice, we define some important technical variables (Table 1) for the platforms previously presented.

The decisive criterion of our choice was the documentation available on the integration of the social network chosen by the Moodle platform. For this, our choice has focused on the Mahara platform; the integration documentation is very available [ 19], and its features meet perfectly our needs.

\section{PROPOSAL}

Many works in social psychology have highlighted the impact of forms of interactions or social memberships on the cognitive mechanisms [20], as well as the importance of social factors in cognitive development, including the acquisition of cultural knowledge [21].

In this perspective, we propose to integrate the social network "Mahara" to our learning platform "Moodle", which renamed "SocioMoodle ", and we exploit the traces produced on this workspace to generate the new social indicators by our system SYMPA (System of modeling profile learner), and in order to help tutor to make a best decision in the best time.

For the establishment of our proposal, we have adopted the following approach:
- Make a thorough study of the features of social networks the most used and identify internet users within these environments

- Make a study on the social networks open source available, and make the choice of the social network that best suits our needs.

- Integrate the social network to the platform used by the university (Moodle).

- Experiment with the complete system Moodle+ social network(SocioMoodle) in a real context of training

- Analyze the collected data and calculate the social indicators using our system SYMPA (system of modeling profile learner).

\section{EXPERIMENTATIONS}

\section{A. Target Audience}

The duration of our first experimentation was spread over thirty weeks with 140 learners. The first batch of students who have made the experiment are the students of MQL (Master Quality Software) graduation 2011/2012, they have worked on varied subjects of application development. The second batch concerned students from ENSA (National School of Applied Science) graduation 2011/2012 who have all worked on some subject of application development.

The second experiment was conducted with the learners of MQL (Master Quality Software) of Kenitra, graduation 2012/2013, and the students of the ENSA (National School of Applied Science) graduation 2012/2013, during a period of 14 weeks. The tutor of MQL asked students to develop different application by group, and the tutor of ENSA gave the same subject, of application development, to all learners. To succeed our experiment, we asked learners to:

- To be connected daily to the platform.

- To created their public page on Mahara platform.

- To integrated their documents (Files,script,PDF...) on the platform.

- To create a group for a work.

- To create a page of group on Mahara

\section{GenERAL PRESENTATION OF SYMPA}

\section{A. Overview of SYMPA}

Our System of Modeling Profile Learner SYMPA, exploits the traces generated by the learners to produce social indicators, which will help the tutor to identify a social profile for each learner.

The social profile of the learner depends on his social production; it means by the number of Tags, comments, or sharing produced by the learner.

Our SYMPA (Figure2) is composed of three components: a component which is engaged in the collection of the traces generated by the learners, the second which is the treatment of 
traces and the calculations, and the last component for the generation of profiles.

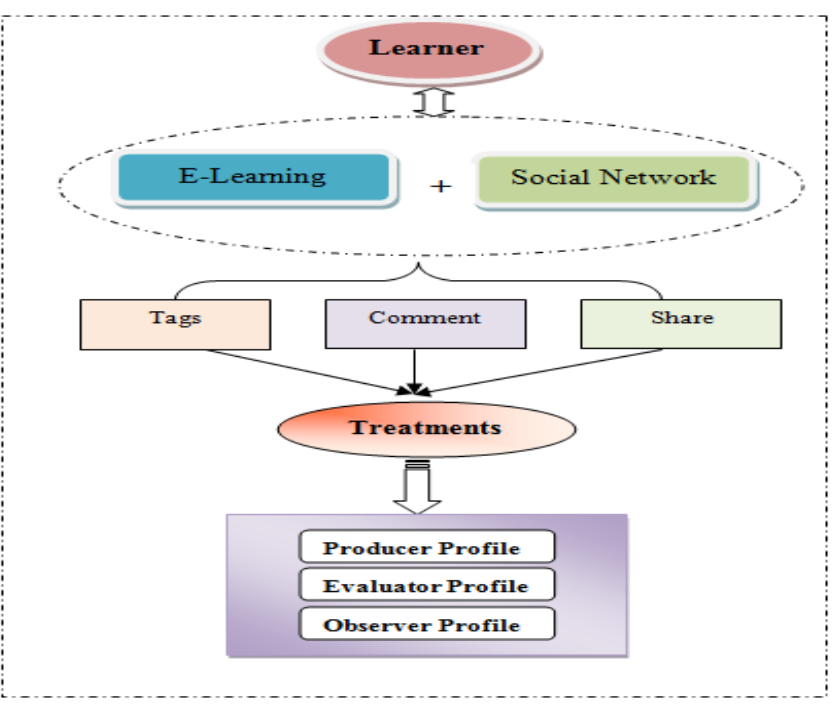

Fig.2. Modeling of SYMPA

In our case, the variable of the time is a parameter taken by the component "treatment" in order to assess the profile of the learner during the period of the training.

\section{B. The Socials Profiles Learners}

With the advent of Information and communication technology (ICT), we talk about "Social Learning" which allows the collaborative learning exchange between individuals. Students learn how to communicate, eventually to reformulate for a better understanding. During the collaborative learning, the exchanges resulting from it are substantial; they allow students to get feedbacks and get back to their learning. Through social networks, we will allow the learners to be better at sharing and comparing their knowledge, offering a new style of dialogue.

Olivier Le Deuff[22] in an article in his blog "Guidedesegares.info" investigated on the concept of social networks made for leisure, as new ways of learning. It shows that people have developed skills beyond the mere techniques of creative leisure. It shows that people can progress in that field and take part of it.

Therefore, we can deduce that the innovation of distance learning, using social networking encourages inter-student interactions between teachers and students; it also highlights the educational resources brought by digital platforms, which prompt users to learn collaboratively.

In a distance learning situation, the characteristics of different social behaviors are among learners. However, distance and media exchanges do not make as immediate perception of these social behaviors. To overcome this limitation, we believe it is useful to have a computer system that can automatically analyze these behaviors.
In particular, in the context of online education, it is interesting to try to determine automatically profiles of social behavior among learners, as they can be useful both for the tutor and learners themselves.

So each learner connected to the platform produces a set of acts that we have previously presented (sharing tags, sharing documents, sharing comment). These acts are represented by the traces; they are stored at the database level. Using our system SYMPA, will allow us to classify them according to their types of actions and define profiles learners.

For our case and based on the work of Plety [23], we have defined three sets of profiles:

TABLE.II. The Profiles of LEARNERs Following A PERSONAL SYNTHESIS OF THE WORK OF PLETY .

\begin{tabular}{|l|l|l|}
\hline Profile & $\begin{array}{l}\text { Main Acts on the } \\
\text { platform }\end{array}$ & $\begin{array}{l}\text { Volume of participation of other } \\
\text { acts }\end{array}$ \\
\hline Producer & Share & Important/Medium/Low \\
\hline Evaluator & Comment & Medium/Low \\
\hline Observer & Tags & Low \\
\hline
\end{tabular}

After the definition of the social profiles, with which we have chosen to classify our learners, we present in the next paragraph the steps of their modeling.

\section{Modeling of Collecting Data}

\section{A. Presentation of the Modeling}

Our job is to analyze the traces generated at the level of our experimentation \{Tags (Tag), Comment (Cmt), Sahre (Prtg)\}, and modeling the profile of the learner through the use of fuzzy set. For each element of the set $\{\mathrm{Tag}, \mathrm{Cmt}, \mathrm{Prtg}\}$, we will get a value that characterized the profile.

The choice of fuzzy logic for modeling the data collected is explained by the relative nature of this data, which designate knowledge that is not perceived or defined clearly.

The positioning of the learner profile according to the fuzzy logic is due to the combination of entered elements $\{\mathrm{Tag}$, CMT, Prtg \}, with their degree of importance \{Low, Medium, High\}.

\section{B. Steps of Fuzzy Logic}

- Step of Fuzzification

This step has for aim to transform the variables of digital inputs in linguistic variables [24]. For our system we have as variables of entered the values below:

- Percentage of share Pctg(Prtg): It is the percentage of documents that share a learner on the platform (Figure 3).

- Percentage of comments Pctg(CMT) : it is the percentage of comments filed by a learner on the shared documents on the platform (Figure 4). 
- Percentage of tags Pctg(Tags): this is the percentage of tags that a learner has marked on documents or comments shared on the platform (Figure 5).

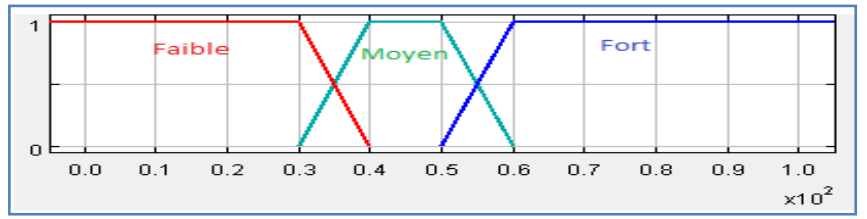

Fig.3. Function belonging to Tags

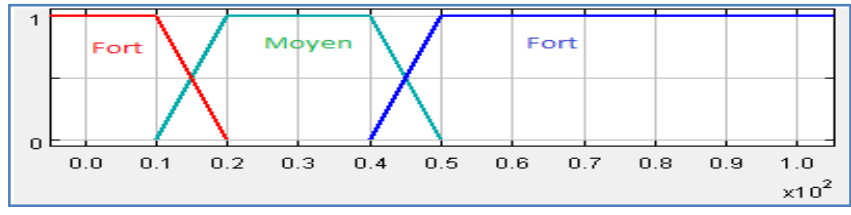

Fig.4. Function belonging to Share

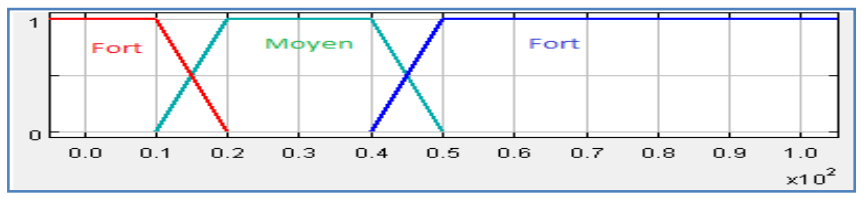

Fig.5. Function belonging to Comments

As output variable, we get the profile of the learner \{Observer profile, Creator Profile, Producer Profile\}, defined as follows (Figure 6).

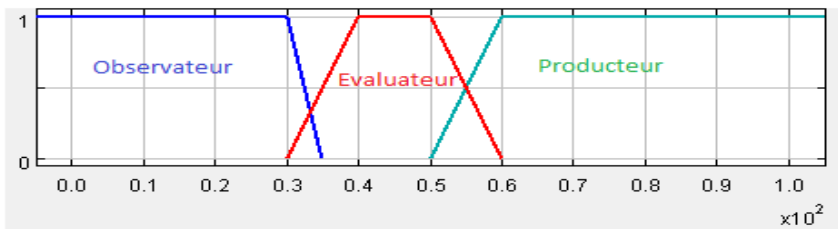

Fig.6. Function belonging to the output

\section{- Step of Rules Inferences}

The rules of fuzzy logic are of the form "If (X is $\mathrm{A}$ ) then ( $\mathrm{Y}$ is B) "with the fuzzy variable $\mathrm{X}$ which belongs to the Class A with a certain degree of membership and in the same way, the variable $\mathrm{Y}$ belongs to the class $\mathrm{B}$ with a degree of membership [25]. Below is sample of rules of our system:

If (Percentage share is Low) and (Percentage Tag is Low) and (Percentage Comments is Fort)

Then (Evaluator Profile)

If (Percentage share is Strong) and (Percentage Tag is Low) and (Percentage Comments is Fort)

Then (Producer Profile)

- Step of Defuzzification

The last step to have a blur system operational is called the defuzzification. During the second step, it has generated a lot of commands in the form of linguistic variables (one command per rule). The purpose of the defuzzification is to merge these commands and to transform the resultant settings into digital data [26].
Under the fuzzy set associated to the output variable are \{Observer, Evaluator, Producer\}.

The generation of the output variable is done by the system by using the method of the center of gravity, depending on the result, we determine the profile learner ( Figure 6).

\section{Results}

The beaches of the results obtained according to the statistics of our experimentation, are as follows (Figure 6):

- Between $0 \%$ and 35\% the result is Observer Profile.

- Between 30\% and 70\% the result is Evaluator Profile.

- Between 65\% and 100\% the result is Producer Profile.

To give a tutor interface to observe the social profile of each learner, we develop a new model in the platform "Moodle", in the Figure 7 an example of profile learner according to time, the blue color present "Observator Profile" , when the learner change the kind of contribution \{Comment , Share , the learner have a new Profile\{Evaluator, Producer\}.

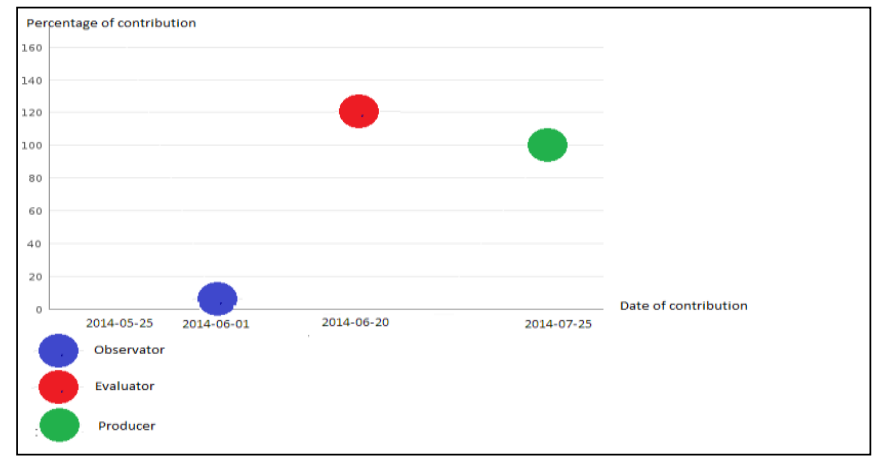

Fig.7. Viewing social profiles on Moodle

In addition, to validate our model, we have asked our tutor to make an assessment of their students and to assign a profile to each learner from their perceptions and what they observed during experimentation.

We have compared the experimental results obtained with the perception of the tutor, and we have noticed a great similarity in the results (table III).

TABLE.III. COMPARISON BETWEEN THE VALUES OF THE GUARDIAN AND THE MODEL OF POSITIONING

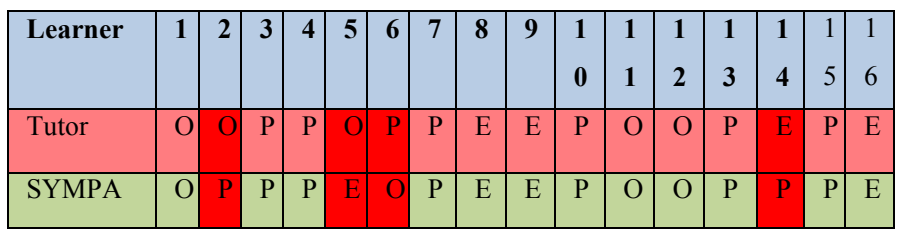

The difference noticed between a few profiles of learners defined by the tutor, can be explained either by the timidity of the learners during the sessions of courses or directed tasks (case of learners 2, 5), the preferences for the use of the 
platform (case of learners 14), or technical problems on the platform (case of learners 6).

\section{CONCLUSION}

In this paper we presented a method for modeling social profile learner, in the "Moodle" system powered by the social network "Mahara". Calculating the learner profile is influenced by among others inaccuracy, due to errors and approximations involved in gathering information, for this we used the method of fuzzy logic.

In this article, we have also presented the results of our experiments to validate our model for positioning the social profiles of learners in distance education; our job is to guarantee a better analysis of the different tracks that were produced by students in our experiment, to generate social indicators. With the help of our system SYMPA, the tutor can optimize his interventions with the learners: motivate, encourage, warn etc.

The results of our experiments were encouraging, and the profiles determined by the expert tutor were very close to the values given by our system SYMPA.

Our next goal is to analyze the traces obtained at the platform for more social indicator of learners.

\section{REFERENCES}

[1] Bernatchez, J. et Gendreau, L. (2005). L'opération « contrat de performance » des universités québécoises : dans la perspective de l'objectif de réussite étudiante.

[2] Rob Reinhardt ,2011, About social community network features

[3] Encyclopedia Britannica, 2008. «Encyclopedia Article for blog »

[4] BoLeuf and WardCunningham. ,2002, The WikiWay, by your hosts

[5] Monox,2010,Social Networking features

[6] Shama Kabani's book The Zen of Social Media: An Easier Way to Build Credibility 2013.
[7] Julie Wittes Schlack, Michael Jennings, Manila Austin « Meeting Business Needs by Meeting Social Needs in Small Communities,2007 ».

[8] Dachary, Use the Right Tools for the Job, March 9, 2010.

[9] Cédric Lemery, « Du web 2.0 à l'éducation 2.0 ? , 2007.

[10] Alan Cann, les réseaux sociaux améliorent la compréhension de la formation ,2010

[11] Jean-Paul Pinte, Les réseaux sociaux sont des outils d'apprentissage en devenir, 2009 .

[12] Terry Anderson, Le Web 2.0, les réseaux sociaux et l'éducation. Les environnements technologiques, les standards et les pratiques innovantes.2009

[13] Timothée Sicot, SMS et réseaux sociaux améliorent l'écriture des étudiants, 2013

[14] http://docs.moodle.org/27/en/Features

[15] Viva Logo Design Resources, 2011 Top 40 free downloadable open source social networking software

[16] Elgg - Logiciel de réseau social Open Source,2004

[17] Oxwall,Start a social network,a fan site,an education project with Oxwall-fee open source community software, 2010.

[18] LiveStreet CMS, LiveStreet CMS is a great tool to create social networks and team blogs, 2010.

[19] Mahara, « Mahoodle :Integrating Mahara with Moodle »

[20] Sherif, M. et alii, 1988. The Robbers Cave Experiment: Intergroup Conflict and Cooperation. Middletown (Conn.), Wesleyan University Press.

[21] Doise, W. et Mugny, G., 1997. Psychologie sociale et développement cognitif. Paris, Armand Colin.

[22] Olivier Le Deuff ,2010 « Réseaux de loisirs créatifs et nouveaux mode d'apprentissage», Distances et savoirs. Vol.8, n 4, p.601-621.

[23] Robert Pléty ,l'apprentissage coopérant, Ethologie et psychologie des communications. [24]William DERIGENT, Vincent BOM BARDIER « Extraction de connaissances et reconnaissance Automatique d'entités minces en aéronautique par Règles linguistiques floues»; 11ème Colloque National AIP PRIMECA La Plagne - 22-24 avril 2009.

[24] Franck Dernoncourt, Le raisonnement en logique floue,2013

[25] Gerald huguenin, Processeurs Floushe-arc, baptiste savoye 26, ch-2610 st-imie 